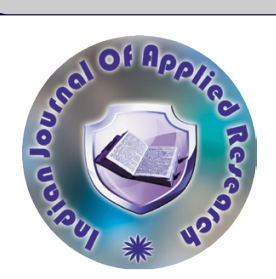

Anaesthesiology

\title{
A STUDY ON ANALGESIA PROVIDED BY ULTRASOUND GUIDED FASCIA ILIACA COMPARTMENT BLOCK WITH AND WITHOUT PARACETAMOL: EFFECT ON HEMODYNAMICS DURING INTUBATION
}

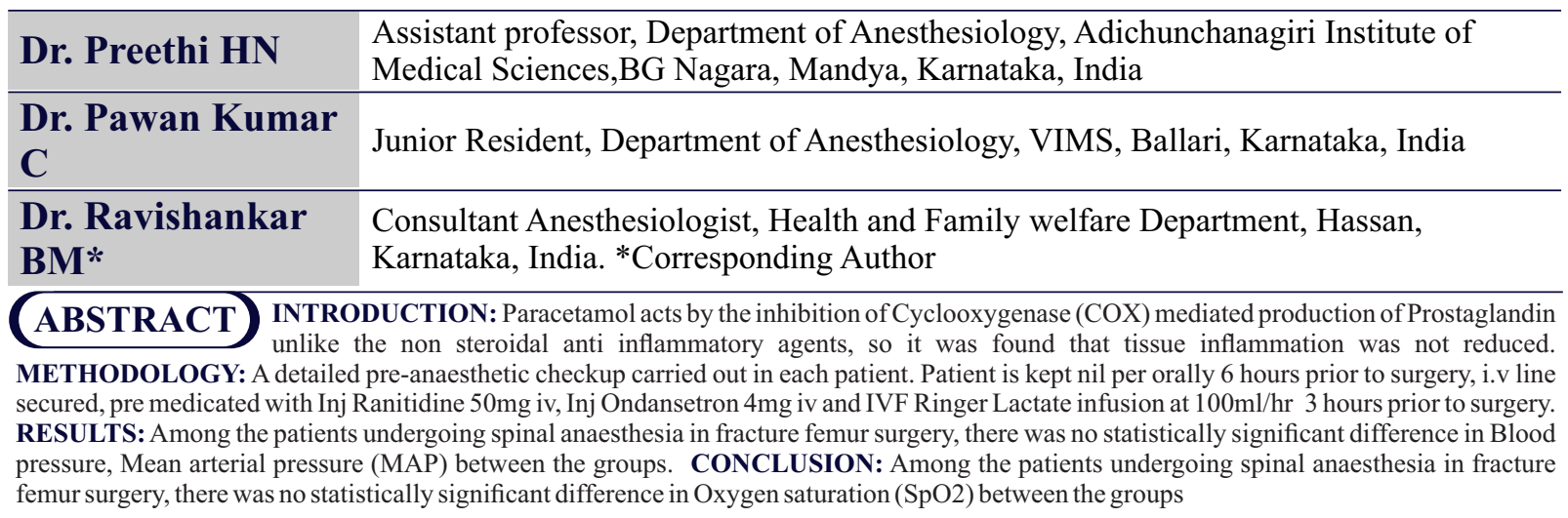

\section{KEYWORDS : Ultrasound Guided Fascia Iliaca Compartment Block, Hemodynamics, Paracetamol}

\section{INTRODUCTION:}

Ultrasound uses sound waves to produce an image of structures through which they pass. Ultrasound waves are emitted from piezoelectric crystals present in the probe of the ultrasound transducer. When an electric current is applied to these crystals, they rapidly change shape and vibrate and emit ultrasound waves. ${ }^{1}$ The process converts electrical energy into mechanical energy and is called reverse piezoelectric effect. These waves travel at different rates through tissues with different densities and return the signal back to the transducer. The crystals convert the mechanical energy of the returning echoes to an electric current (piezoelectric effect) that is converted into a two dimensional grayscale image. Hence the same crystals are used to send and receive the sound waves.

Paracetamol acts by the inhibition of Cyclooxygenase (COX) mediated production of Prostaglandin unlike the non steroidal anti inflammatory agents, so it was found that tissue inflammation was not reduced ${ }^{4}$.

In intact cells levels of arachidonic acid were found to be low so the potent inhibitory action of Paracetamol on Prostaglandin synthesis blocks the physiological regeneration of Peroxidase $(\mathrm{POX})^{5}$.

In broken cells concentration of Hydroperoxidase was found to be high; hence Prostaglandin synthesis inhibited weakly. This explains the differential activity of Paracetamol in the brain where peroxide concentrations are low and in peripheral sites of inflammation the levels were high. Hence at the site of injured or inflamed tissue it provides highly effective analgesia and antipyretic effects; but there is lack of anti inflammatory and anti platelet activity ${ }^{6}$

Another pathway of action is by the activation of descending serotonergic pathway. Paracetamol also has an endocannabinoid enhancement activity which explains the experience of relaxation, tranquility and euphoria reported in many users apart from the analgesic effects.

\section{METHODOLOGY:}

GROUP 1: Patients will receive ultrasound guided fascia iliaca compartment block with $30 \mathrm{ml}$ of $0.5 \%$ Ropivacaine with 30 min prior administration of $100 \mathrm{ml} \mathrm{NS} \mathrm{I.}$

All patients with femoral fractures undergoing surgery under central neuraxial anaesthesia will be enrolled for the study.

A detailed pre-anaesthetic checkup carried out in each patient. Patient is kept nil per orally 6 hours prior to surgery, i.v line secured, pre medicated with Inj Ranitidine 50mg iv, Inj Ondansetron $4 \mathrm{mg}$ iv and IVF Ringer Lactate infusion at $100 \mathrm{ml} / \mathrm{hr} 3$ hours prior to surgery. On arrival to Operation theatre, standard monitors including ECG, Pulse oximeter, and non invasive blood pressure will be attached and baseline vital parameters will be recorded.

GROUP 2: patients will receive fascia iliaca block with $30 \mathrm{ml}$ of $0.5 \%$ of Ropivacaine with 30min prior administration of inj Paracetamol 1g . Central neuraxial anesthesia will be performed in these patients after 30 minutes of giving block in lateral dependent position on the fractured site.

When a patient reported a NRS $\geq 4$ during this positioning, the procedure was stopped, and $100 \mathrm{mcg}$ of i.v. fentanyl was administered in both groups. Positioning was reattempted after NRS $<4$.

\section{INCLUSION CRITERIA:}

- Patients belonging to ASA grade I and II.

- Patients of either sex, between the age group 20 to 80 years.

- Patients with fracture femur, posted for surgery under subarachnoid block.

- Patients who give a valid informed consent.

\section{EXCLUSION CRITERIA:}

- Patients not satisfying inclusion criteria.

- Patients belonging to ASA grade III or IV.

- Patients with hemorrhagic diathesis, neurological disorders, psychiatric disorders.

- Previous femoral bypass surgery.

- Patients with allergy to local anaesthetics or paracetamol.

- Patients with polytrauma, infection over the injection site

- Patients with liver diseases

- Morbid obesity.

- Patients who will be administered with supplementary epidural or general anaesthesia.

- Patients with spinal deformities.

Hemodynamic variables like heart rate, non invasive blood pressure, saturation of oxygen, respiratory rate were recorded prior to administration of inj paracetamol or $0.9 \% \mathrm{NS}$, when shifted to the operation room, after FICB block, at five minutes intervals till positioning.

\section{RESULTS:}

Table 1: HEART RATE

\begin{tabular}{|l|l|l|l|l|l|l|}
\hline \multicolumn{1}{|l|}{ BASE LINE } & \multicolumn{2}{l|}{ 30 MIN } & \multicolumn{2}{l|}{ POSITIONING } \\
\hline & MEAN & SD & MEAN & SD & MEAN & SD \\
\hline GROUP A & 82.269 & 13.987 & 87.576 & 13.609 & 84.423 & 14.703 \\
\hline GROUP B & 86.566 & 13.187 & 88.733 & 14.451 & 86.9 & 15.696 \\
\hline P VALUE & 0.242 & 0.909 & 0.547 & \\
\hline
\end{tabular}

Among the patients undergoing spinal anaesthesia in fracture femur 
surgery, there was no statistically significant difference in Heart rate (HR) between the groups . Group A at baseline (mean=82.269, $\mathrm{SD}=13.987)$, after 30 minutes (mean=87.576, $\mathrm{SD}=13.609)$, during positioning (mean=84.423, $\mathrm{SD}=14.703)$ and Group $\mathrm{B}$ at baseline (mean $=86.566, \mathrm{SD}=13.187)$, after 30 minutes $($ mean $=88.733$, $\mathrm{SD}=14.451)$, during positioning $($ mean $=86.9, \mathrm{SD}=15.696)$ with a $\mathrm{p}$ value of $>0.05$ as per unpaired $t$ test. Therefore we fail to reject the null hypothesis that there is no difference in the Heart rate (HR) between the intervention groups.

Table 2: BLOOD PRESSURE (MEANARTERIAL PRESSURE)

\begin{tabular}{|c|c|c|c|c|c|c|}
\hline & \multicolumn{2}{|c|}{ BASE LINE } & \multicolumn{2}{|l|}{30 MIN } & \multicolumn{2}{|c|}{ POSITIONING } \\
\hline & MEAN & $\mathrm{SD}$ & MEAN & SD & MEAN & SD \\
\hline GROUP A & 101.385 & 14.851 & 93.807 & 13.396 & 92.615 & 14.876 \\
\hline GROUP B & 93.808 & 13.396 & 88.733 & 14.451 & 92.666 & 14.451 \\
\hline P VALUE & 0.1238 & & 0.9091 & & 0.9968 & \\
\hline
\end{tabular}

Among the patients undergoing spinal anaesthesia in fracture femur surgery, there was no statistically significant difference in Blood pressure, Mean arterial pressure (MAP) between the groups . Group A at baseline (mean=101.385, $\mathrm{SD}=14.851)$, after 30 minutes (mean=93.807, $\mathrm{SD}=13.396$ ), during positioning (mean=92.615, $\mathrm{SD}=14.876$ ) and Group B at baseline (mean $=93.808, \mathrm{SD}=13.396)$, after 30 minutes (mean=88.733, $\mathrm{SD}=14.451$ ), during positioning (mean $=92.666, \mathrm{SD}=14.451$ ) with a $\mathrm{p}$ value of $>0.05$ as per unpaired $\mathrm{t}$ test. Therefore we fail to reject the null hypothesis that there is no difference in the Blood pressure, Mean arterial pressure (MAP) between the two groups.

Table 3: O2 SATURATION (SPO2)

\begin{tabular}{|c|c|c|c|c|c|}
\hline \multirow[t]{2}{*}{ TIME } & \multicolumn{2}{|c|}{ GROUPA } & \multicolumn{2}{|c|}{ GROUP B } & \multirow[t]{2}{*}{ PVALUE } \\
\hline & $\begin{array}{l}\text { MEAN } \\
\text { (SpO2) }\end{array}$ & SD & $\begin{array}{l}\text { MEAN } \\
\text { (SpO2) }\end{array}$ & SD & \\
\hline BL & 97.385 & 1.619 & 98.033 & 1.2452 & 0.0967 \\
\hline $30 \mathrm{MIN}$ & 97.8461 & 1.2551 & 97.767 & 1.4308 & 0.8261 \\
\hline Positioning & 97.8076 & 1.1668 & 97.8 & 1.78274 & 0.9502 \\
\hline
\end{tabular}

Among the patients undergoing spinal anaesthesia in fracture femur surgery, there was no statistically significant difference in Oxygen saturation $(\mathrm{SpO} 2)$ between the groups . Group $\mathrm{A}$ at baseline (mean=97.385, $\mathrm{SD}=1.619$ ), after 30 minutes (mean=97.846, $\mathrm{SD}=1.2551$ ), during positioning (mean=97.8076, $\mathrm{SD}=1.1668)$ and Group B at baseline (mean=98.033, $\mathrm{SD}=1.2452$ ), after 30 minutes (mean=97.767, $\mathrm{SD}=1.4308)$, during positioning (mean=97.8, $\mathrm{SD}=1.7827$ ) with a $\mathrm{p}$ value of $>0.05$ as per unpaired $t$ test. Therefore we fail to reject the null hypothesis that there is no difference in the Oxygen saturation ( $\mathrm{SpO} 2)$ between the intervention groups.

\section{DISCUSSION:}

Spinal anaesthesia is the most commonly used anaesthetic technique of choice in orthopaedics for lower limb fractures. While regional anaesthesia has been shown to be more beneficial compared to general anaesthesia, patient positioning for neuraxial blockade may cause severe pain in patients with femur fractures. Various systemic analgesics are being used to provide pain relief during positioning in these patients. Among the systemic analgesics, opioids are widely used but they are known to be associated with side effects like cognitive impairment, vomiting, urinary retention, respiratory depression especially in the elderly. Nerve blocks like the 3 in 1 block, femoral nerve block, fascia iliaca compartment block have all come up as an alternative approach to provide pain relief and improve positioning in these patients?

Fascia iliaca compartment block, first described by Dalens et al is a simple,and safe technique that can be used during pre hospital care, emergency department and in the pre operative setting. It blocks the femoral, lateral femoral cutaneous nerve and sometimes the obturator nerve. Also, since the injection is done away from the artery and nerve, there are minimal chances of neurovascular injury. The usage of ultrasound guidance to visualize the fascia iliaca and to deposit the drug beneath it lateral to the femoral nerve increases the success rate of block and further reduces the risk of neurovascular injury ${ }^{8}$.

The recent introduction of paracetamol i.v overcomes the issue of bioavailability compared with oral and rectal routes thereby earlier onset and ease of administration. It demonstrates efficacy comparable with standard equivalents doses of many NSAIDs with fewer side effects. Its therefore virtually used in every anaesthetic management / perioperative pain/multimodal analgesia.

Ropivacaine is a long acting local anaesthetic structurally related to bupivacaine (S-enantinomer) serves the purpose of reducing potential toxicity and improving relative sensory and motor block.

\section{CONCLUSION:}

Among the patients undergoing spinal anaesthesia in fracture femur surgery, there was no statistically significant difference in Blood pressure, Mean arterial pressure (MAP) between the groups.

\section{REFERENCES:}

1. Orosz GM, Magaziner J, Hannan EL, et al. Association of timing of surgery for hip fracture and patient outcomes. JAMA 2004;291:1738-43.

2. Barriot P, Riou B, Ronchi L, Bellaiche S. Femoral nerve block in prehospital management of fractured shaft of femur. JEUR 1988;1:21-24.

3. Daniel Godoy Monzon, Kenneth V. Iserson, and A.Vazquez. Single fascia iliaca compartment block for post-hip fracture pain relief. Doi:10.1016/j.jemermed.2006.08. Urwin SC, Parker MJ, Griffiths R. General versus regional anesthesia for hip fracture surgery: a meta-analysis of randomized trials. Br JAnaesth. 2000;84:450-455.

5. Duc TA. Postoperative pain control. In: Conroy JM, Dorman BH,editors. Anesthesia for Orthopedic Surgery. New York, NY: Raven Press; 1994. p. 355-365.

6. Ting PL, Sivagnanaratnam V. Ultrasonographic study of the spread of local anaesthetic during axillary brachial plexus block. British Journal of Anaesthesia. during axillary brachic

7. Kapral S, Krafft P, Eibenberger K, Fitzgerald R, Gosch M, Weinstabl C. Ultrasoundguided supraclavicular approach for regional anesthesia of the brachial plexus. Anesthesia and Analgesia. 1994;78(3):507-513.

8. Marhofer P, Schrogendorfer K, Koinig H, Kapral S, Weinstabl C, Mayer N Ultrasonographic guidance improves sensory block and onset time of three-in-one blocks. Anesthesia and Analgesia. 1997;85(4):854-857. 